$\overline{\text { REV IE W }}$

\title{
Concurrent chemoradiation in treatment of carcinoma cervix
}

Meeta Singh, Rajshree Jha, Josie Baral, Suniti Rawal

Dept of Obs/Gyn, TU Teaching Hospital, Kathmandu, Nepal.

\begin{abstract}
Aim: to compare if concurrent chemoradiation is better than radiotherapy given alone in the treatment of women with locally advanced cervical cancer from published literature

Method: Study Design: Randomized control trials of $>$ than 2, 403 women participants who underwent treatment for advanced cervical carcinoma mainly in two huge center i.e. from National Cancer Institute (NCI), USA and European Organization for Research and Treatment of Cancer (EORTC) were reviewed regarding the treatment they received at the center: concurrent chemoradiation/ radiation therapy alone. The results were analyzed to come to conclusion.

Result demonstrated a 30-50\% improvement in survival when cisplatin-based chemotherapy in $\mathrm{NCl}$ or 5 fluorouracil and cisplatin based chemotherapy was used in EORTC was administered with concurrent radiation therapy (chemoradiation)

Conclusions: The addition of chemotherapy (cisplatin) in $\mathrm{NCl}$ and (cisplatin and fluorouracil) in the EORTC for the treatment of locally advanced cervical cancer with the concurrent chemoradition have elicited better survival than those treated with radiotherapy alone dittoed by several other trials which can be anticipated to benefit Nepalese women with locally advanced cervical carcinoma.
\end{abstract}

Key-words: Cancer cervix, chemoradiation, radiotherapy

Global burden from cervical carcinoma accounts $6 \%$ of all malignancies in women, thus remaining as one of the greatest killer worldwide. In the estimated 13,700 women in the United States in whom invasive cervical cancer was diagnosed in 1998, nearly 5000 would ultimately die of the disease because of the inadequacies of current treatment. ${ }^{1}$ According to Globocan, numbers of patients diagnosed and died from this disease were 470,606 and 233,372, respectively. ${ }^{2}$ It is remarkable that these rates occur, despite the fact that cervical cancer is a model for early detection, having relatively well-known natural history that offers an excellent opportunity for its detection before lesions become invasive. ${ }^{3}$

The recommended treatment for IA 1 patients is either a local procedure such as conization or total hysterectomy, depending on the patient's desire to remain fertile, whereas for IA2 patients the recommendation is for a radical surgery. On average,
$8 \%$ of cases show positive pelvic lymph nodes. In surgically treated early-stage cases, the presence in the surgical specimen of a combination of intermediaterisk factors (vascular and lymphatic permeation, tumor size $>2 \mathrm{~cm}$, and deep cervical stroma invasion) or highrisk factors (positive pelvic lymph nodes, parametrial infiltration, and positive surgical margins) dictates the use of adjuvant radiation. ${ }^{4}$

Globally, the majority of cancers are locally advanced at diagnosis; hence, radiation remains the most frequently used therapeutical modality.

Chemoradiation proposes to remedy many women with carcinoma of cervix detected in advanced stages which in the past few years have increased immensely and benefiting from the treatment with observed better progression free and overall survival. Because in these locally advanced malignancies, radical surgery is far from optimal. Although the standard radical surgery

\section{Correspondence}

Dr Meeta Singh, $M D$

Associate professor, Dept of Obs/Gyn, TU Teaching Hospital, Kathmandu, Nepal.

Email.singhmita@hotmail.com 
for early cancer cervix by radical hysterectomy removes uterus, parametrial tissue, upper vagina and pelvic lymph nodes has often been accepted. For the past decade to preserve fertily in women having early cervical cancer, some Gynecological Oncologist have advocated radical trchelectomy instead of radical hysterectomy. Bearing in mind that there is tendency of lateral spread into the parametria and lymph nodes rather than vertically into the uterus or vagina, removal of cervix, parametria and lymph nodes were considered as prime treatment preserving vagina, uterus and ovaries.

A radical surgical procedure for locally advanced cervical malignancy fails to be treated successfully and such cases would benefit from concurrent chemoradition. Cisplatin used during radiation 'concurrent chemoradiation' for various stages of cancer cervix had better results than those treated alone by radio therapeutic regimen with improvement on survival compared with radiotherapy alone. Although it is widely accepted that cisplatinumbased chemoradiation is the standard treatment regimen; optimal scheduling and dosing have yet to be finalized.

Women with early cervical cancer are treated with radical surgery and those with a large cervical lesion at presentation or with spread to the pelvic lymph nodes or other pelvic tissues are usually treated with a combination of external-beam and intracavitary radiation (5-9). Even in the United States, the estimated 13,700 women in whom invasive cervical cancer was diagnosed in 1998, nearly 5000 were deemed to die ultimately of the disease because of the inadequacies of current treatment. ${ }^{1}$ Treatment results for locally advanced stages are far from optimal. In this regard, treatment of locally advanced cervical cancer experienced no major changes for the nearly 80 years during which exclusive radiation was considered the standard of care; thus, 5-year survival for stages IB2, IIB, IIIB, and IVA are 72.2, 63.7, 41.7, and $16.4 \%$, respectively, according to the 1998 Annual Report on the Results of Treatment in Gynecological Cancer. ${ }^{10}$ The lengthy permanence of this unimodal treatment was due, on the one hand, to the classical concept that cervical cancer is a disease that progresses in an orderly fashion (local, then regional, and at the very last, systemic); therefore, it could be effectively treated with a local modality such as radiation instead of a systemic modality such as chemotherapy. On the other hand, the role of surgery for locally advanced cases failed to treat the disease successfully by radical surgical procedures. $^{11}$

Trials testing concurrent chemoradiation over the past few years attempting to improve treatment results and to eradicate micro metastases and sensitize tumor cells to radiation, have explored radiotherapy with concomitant chemotherapy. ${ }^{12-15}$ It was not until 1999 that five randomized studies including nearly 2,000 patients were published, demonstrating that survival rate with concomitant chemotherapy (RT/CT) based on cisplatin was superior than that obtained with radiation alone. ${ }^{16-20}$ Afterwards, a meta-analysis based on 19 trials (17 published and two unpublished) including 4,580 patients corroborated these findings, confirming that chemoradiation offers an absolute survival benefit of $12 \%$ at 5 years. ${ }^{21}$ The concurrent chemotherapy and radiation (chemoradiotherapy) of loco regionally advanced cervical cancer has dramatically improved the local control and overall survival compared with the traditional therapy with radiation. ${ }^{22}$ Recent results from each of 5 randomized phase III trials show an overall survival advantage for cisplatin-based therapy given concurrently with radiation therapy. The patient populations in these studies included women with FIGO stages IB2 to IVA cervical cancer treated with primary radiation therapy and women with FIGO stages I to IIA disease found to have poor prognostic factors (metastatic disease in pelvic lymph nodes, parametrial disease, or positive surgical margins) at time of primary surgery. Although the trials vary somewhat in terms of stage of disease, dose of radiation, and schedule of cisplatin and radiation, they all demonstrate significant survival benefit for this combined approach. The risk of death from cervical cancer was decreased by $30 \%$ to $50 \%$ by concurrent chemoradiation.

National Cancer Center released a clinical alert to practicing oncologists on February $23^{\text {rd }} 1999$, based on significant improvement in both progression-free survival and overall survival when cisplatin-based chemotherapy was administered during radiation for various stages of cervical cancer. ${ }^{23-28}$ This clinical alert outlined the findings of the five clinical trials that had been completed and recommended strong consideration should be given to the incorporation of concurrent cisplatin-based chemotherapy with radiation therapy in women who require radiation therapy for treatment of cervical cancer."(29) These five randomized trials, involving 2,000 women, demonstrated a $30 \%$ to $50 \%$ improvement in survival when cisplatinbased chemotherapy was administered concurrently with radiation therapy.

The evidence from all five trials for reduction in the isk of death with concurrent cisplatin-based chemotherapy and radiation therapy compared with their respective control groups showed the reductions in risk and the 95\% confidence intervals for the cisplatin-based chemoradiation treatment groups. Compared with the control group, the NCIC trial observed a $12 \%$ lower death rate for the chemoradiation group. Simlar result with the European Organization for Research and Treatment of Cancer was shown with flurouracil and cisplatinum based chemotherapy. 
Cisplatin although it is widely accepted that cisplatinbased chemoradiation is the standard treatment for locally advanced cervical carcinoma, optimal scheduling and dosing have yet to be established. Evidence from the GOG125 study indicates that weekly cisplatin at $40 \mathrm{mg} / \mathrm{m}^{2}$ for six weeks is equally effective yet less toxic than cisplatin and 5-fluorouracil in a classic 21-day schedule (30); nonetheless, the choice of $40 \mathrm{mg} / \mathrm{m}^{2}$ as the dose for weekly cisplatin for phase III chemoradiation trials was not based on previous phase I data, and the maximum tolerated dose of weekly cisplatin in combination with pelvic radiation has not been clearly defined. However, indirect data from subsequent studies of chemoradiation in non-protocol settings suggest that this dose of cisplatin is perhaps the maximum tolerated. For instance, Abu-Rustum ${ }^{31} \mathrm{et}$ al reported on 65 women from minorities (AfricanAmerican, Caucasian, and Hispanic) receiving weekly cisplatin during radiation; overall, 19 of 65 (29.2\%) patients had incomplete chemotherapy, nine due to hematological or renal toxicity. Thus, only seven patients $(10.8 \%)$ received six cycles of cisplatin, although the majority $(60 \%)$ received five applications. ${ }^{32}$ In another report, 112 patients with cervical cancer received five planned courses of cisplatin at $40 \mathrm{mg} / \mathrm{m}^{2}$ during external radiation; 62 patients $(55 \%)$ did not undergo the five planned cycles of cisplatin due to treatment toxicity $(31 \%)$ or noncompliance due to delayed first-cycle administration or omission of a cycle for reasons other than toxicity $(21 \%) .{ }^{33}$ Cisplatin has become a standard part of the treatment, but still there is uncertainty about dose and schedule are optimal or whether it is possible to achieve even better efficacy with some other drugs or drug combinations. Clinical trials with some other drugs or drug combinations will ultimately resolve this issue, currently, the value of adding cisplatin or cisplatinbased chemotherapy to radiation for treatment of locally advanced cervical cancer is strongly supported by randomized studies and meta-analyses. Nevertheless, despite these significant achievements, therapeutic results are far from optimal.

\section{Conclusion}

Concurrent chemoradition, in which cisplatin or its combination with flurouracil based chemotherapy is administered during radiation for carcinoma cervix in various stages of locally advanced diseases were observed to provide better progression free or overall survival than those treated alone with radiotherapy, collectively gained from the five major trials favoring use of combined chemoradiation. Nepalese women with advanced cervical carcinoma would definitely benefit utilization this therapy and such therapy should be advocated.

\section{Reference}

1. Landis SH, Murray T, Bolden S, Wingo PA. Cancer statistics, 1998. CA Cancer J Clin 1998; 48: 6-29. [Erratum, CA Cancer J Clin 1998; 48:192.] Parkin DM, Bray F, Ferlay J, Pisani P: Estimating the world cancer burden: Globocan 2000 Globocan 2000

2. Richart RM, Barron BA: A follow-up study of patients with cervical displasia. Am J Obstet Gynecol 1969, 105:386-371.

3. Sedlis A, Bundy BN, Rotman MZ, Lentz SS, Muderspach LI, Zaino RJ: A randomized trial of pelvic radiation therapy versus no further therapy in selected patients with stage IB carcinoma of the cervix after radical hysterectomy and pelvic lymphadenectomy: A Gynecologic Oncology Group Study. Peters WA 3rd, Liu PY, Barrett R, Stock RJ, Monk BJ, Berek JS, Souhami L, Grigsby P, Gordon W Jr, Alberts DS: Concurrent chemotherapy and pelvic radiation therapy compared with pelvic radiation therapy alone as adjuvant therapy after radical surgery in highrisk early-stage cancer of the cervix. J Clin Oncol 2000, 18:1606-1613.

4. Annual Report on the Results of Treatment in Gynaecological Cancer J Epidemiol Statist 1998, 3:5-34.

5. Eifel PJ, Morris M, Wharton JT, Oswald MJ. The influence of tumor size and morphology on the outcome of patients with FIGO stage IB squamous cell carcinoma of the uterine cervix. Int J Radiat Oncol Biol Phys 1994;29:9-16.

6. Eifel PJ, Morris M, Oswald MJ, Wharton JT, Delclos L. Adenocarcinoma of the uterine cervix: prognosis and patterns of failure in 367 cases. Cancer 1990;65:2507-2514.

7. Delgado G, Bundy BN, Fowler WC Jr, et al. A prospective surgical pathological study of stage I squamous carcinoma of the cervix: a Gynecologic Oncology Group study. Gynecol Oncol 1989;35:314-320.

8. Alvarez RD, Soong SJ, Kinney WK, et al. Identification of prognostic factors and risk groups in patients found to have nodal metastasis at the time of radical hysterectomy for early-stage squamous carcinoma of the cervix. Gynecol Oncol 1989;35:130-135. 
9. Stehman FB, Bundy BN, DiSaia PJ, Keys HM, Larson JE, Fowler WC. Carcinoma of the cervix treated with radiation therapy. I. A multi-variate analysis of prognostic variables in the Gynecologic Oncology Group. Cancer 1991;67: 2776-2785.

10. Keys HM, Bundy BM, Stehman FB, et al: A comparison of weekly cisplatin during radiation therapy versus irradiation alone each followed by adjuvant hysterectomy in bulky stage IB cervical carcinoma: A randomized trial of the Gynecologic Oncology Group. N Engl J Med 340: 1154-1161, 1999.

11. National Cancer Institute: NCI Clinical Announcement. Bethesda, MD, United States Department of Health and Human Services, Public Health Service,Peters WA 3rd, Liu PY, Barrett R, Stock RJ, Monk BJ, Berek JS, Souhami L, Grigsby P, Gordon W Jr, Alberts DS: Concurrent chemotherapy and pelvic radiation therapy compared with pelvic radiation therapy alone as adjuvant therapy after radical surgery in highrisk early-stage cancer of the cervix J Clin Oncol 2000, 18:1606-1613.

12. Thomas G, Dembo A, Fyles A, et al. Concurrent chemoradiation in advanced cervical cancer. Gynecol Oncol 1990;38:446-451.

13. Grigsby PW, Graham MV, Perez CA, Galakatos AE, Camel HM, Kao MS. Prospective phase I/II studies of definitive irradiation and chemotherapy for advanced gynecologic malignancies. Am J Clin Oncol 1996;19:1-6.

14. Stehman FB, Bundy BN, Thomas G, et al. Hydroxyurea versus misonidazole with radiation in cervical carcinoma: long-term follow-up of a Gynecologic Oncology Group trial. J Clin Oncol 1993;11:1523-1528.

15. Bauer M, Leibel S, Wasserman T, et al. Effect of misonidazole dose on survival in patients with stage IIIB-IVA squamous cell carcinoma of the uterine cervix: an RTOG randomized trial. Int J Radiat Oncol Biol Phys 1986;12:1101-1103.

16. Rose PG, Bundy BN, Watkins EB, et al: Concurrent cisplatin-based chemoradiation improves progression free and overall survival in advanced cervical cancer: Results of a randomized Gynecologic Oncology Group Study. N Engl J Med 340: 1144-1153, 1999.

17. Whitney CW, Sause W, Bundy BN, et al: A randomized comparison of fluorouracil plus cisplatin versus hydroxyurea as an adjunct to radiation therapy in stages IIB-IVA carcinoma of the cervix with negative para-aortic lymph nodes: A Gynecologic Oncology Group and Southwest Oncology Group Study. J Clin Oncol 17: 1339$1348,1999$.

18. Morris M, Eifel PJ, Lu J, et al: Pelvic radiation with concurrent chemotherapy versus pelvic and para-aortic radiation for high-risk cervical cancer: A randomized Radiation Therapy Oncology Group clinical trial. N Engl J Med 340: 1137-1143, 1999.

19. Peters WA III, Liu PY, Barrett RJ, et al: Cisplatin and 5-fluorouracil plus radiation therapy are superior to radiation therapy as adjunctive in high-risk early stage carcinoma of the cervix after radical hysterectomy and pelvic lymphadenectomy: Report of a phase III intergroup study. J Clin Oncol 18: Rose PG, Bundy BN, Watkins EB, et al: Concurrent cisplatin-based chemoradiation improves progression free and overall survival in advanced cervical cancer: Results of a randomized Gynecologic Oncology Group Study. N Engl J Med 340: 1144-1153, 1999.

20. Keys HM, Bundy BM, Stehman FB, et al: A comparison of weekly cisplatin during radiation therapy versus irradiation alone each followed by adjuvant hysterectomy in bulky stage IB cervical carcinoma: A randomized trial of the Gynecologic Oncology Group. N Engl J Med 340: 1154-1161, 1999.

21. National Cancer Institute: NCI Clinical Announcement. Bethesda, MD, United States Department of Health and Human Services, Public Health Service, 1606-1613, 2000 National Institutes of Health, February 1999.

22. 13Rose PG, Bundy BN, Watkins EB, et al: Concurrent cisplatin-based chemoradiation improves progression free and overall survival in advanced cervical cancer: Results of a randomized Gynecologic Oncology Group Study. N Engl J Med 340: 1144-1153, 1999.

23. 14Rose P. G. Bundy BN, Watkins EB, et al Chemoradiotherapy for cervical cancer. Eur. J. Cancer, 38: 270-278, 2002.

24. 15 Whitney CW, Sause W, Bundy BN, et al: A randomized comparison of fluorouracil plus cisplatin versus hydroxyurea as an adjunct to radiation therapy in stages IIB-IVA carcinoma of the cervix with negative para-aortic lymph nodes: A Gynecologic Oncology Group and Southwest Oncology Group Study. J Clin Oncol 17: 13391348, 1999 
25. Morris M, Eifel PJ, Lu J, et al: Pelvic radiation with concurrent chemotherapy versus pelvic and para-aortic radiation for high-risk cervical cancer: A randomized Radiation Therapy Oncology Group clinical trial. N Engl J Med 340: 1137-1143, 1999

26. Peters WA III, Liu PY, Barrett RJ, et al: Cisplatin and 5-fluorouracil plus radiation therapy are superior to radiation therapy as adjunctive in high-risk early stage carcinoma of the cervix after radical hysterectomy and pelvic lymphadenectomy: Report of a phase III intergroup study. J Clin Oncol 18: 1606-1613, 2000.

27. Rose PG, Bundy BN, Watkins EB, et al: Concurrent cisplatin-based chemoradiation improves progression free and overall survival in advanced cervical cancer: Results of a randomized Gynecologic Oncology Group Study. N Engl J Med 340: 1144-1153, 1999.

28. National Cancer Institute: NCI Clinical Announcement. Bethesda, MD, United States Department of Health and Human Services, Public Health Service, Rose P. G. Chemoradiotherapy for cervical cancer. Eur. J. Cancer, 38: 270-278, 2002.
29. Keys HM, Bundy BM, Stehman FB, et al: A comparison of weekly cisplatin during radiation therapy versus irradiation alone each followed by adjuvant hysterectomy in bulky stage IB cervical carcinoma: A randomized trial of the Gynecologic Oncology Group. N Engl J Med 340: 1154-1161, 1999.

30. Thomas G, Dembo A, Beale F, et al. Concurrent radiation, mitomycin $\mathrm{C}$ and 5-fluorouracil in poor prognosis carcinoma of cervix: preliminary results of a phase I-II study. Int J Radiat Oncol Biol Phys 1984;10:1785-1790.

31. Abu-Rustum NR, Lee S, Correa A, Massad LS: Compliance with and acute hematologic toxic effects of chemoradiation in indigent women with cervical cancer. Gynecol Oncol 2001, 81:8891.

32. Serkies K, Jassem J: Concurrent weekly cisplatin and radiotherapy in routine management of cervical cancer: a report on patient compliance and acute toxicity. Int J Radiat Oncol Biol Phys 2004, 60:814-821.

33. Landis SH, Murray T, Bolden S, Wingo PA. Cancer statistics, 1998. CA Cancer J Clin 1998; 48:6-29. [Erratum, CA Cancer J Clin 1998; 48:192. 